\title{
Historical Overview of Pharmaceutical Industry and Drug Regulatory Affairs
}

\section{Hasumati Rahalkar*}

Founder, Metna Consultants, 1306, Mayuresh Chambers, CBD Belapur,Navi Mumbai- 400 614, Maharashtra, India

\begin{abstract}
In this chapter, we have studied that drug regulations and pharmaceutical industry has developed due to circumstances faced by the Health Authority (HA) at that time. For USA, the root for vaccine industry development was the vaccine tragedy. In response to that The Biologics Act of 1906 came into force shifting vaccine manufacturing from health authority to Vaccine Industry. Due to issue of safety and efficacy, pre-marketing approval with scientific safety data becomes mandatory. These regulations were further defined by classifying drugs into Over-The-Counter (OTC) and Prescription Only category. The USFDA has grown from one chemist to more than 9000 employees currently. In summary, US Health Authority has grown from one chemist to more than 9000 employees, no scientific data to pre marketing approval with scientific data, drug categorization and various regulations for new drugs, biologics as well as marketing authorization.
\end{abstract}

In Europe, due to thalidomide tragedy, 65/65/EEC came into effect mandating marketing authorization. Pharmaceutical legislations pertaining to drug development as well as marketing authorization procedure become quite clear and transparent. EMEA committee was developed for centralised application assessment.

In India, the drug industry has grown from API manufacturing through reverse engineering to pure research and development. Regulatory Authority of India issued guideline for Fixed Dose Combination, Implementation of Common Technical Dossier (CTD), Clinical Trial Registry of India (CTRI) as well as pharmacovigilance cell.

Under Drug Regulatory Affairs section, we have studied the link of Global, Regional as well as National Regulatory Network. We have learnt that Regulatory Affairs professionals are very critical and important for the national and international business of pharmaceutical industry. Regulatory network in pharmaceutical industry indicates that communication and advice to various departments in industry is very essential. He/she plays an active role in defining guidelines nationally and internationally.

Keywords: ANMAT: Administration Nacional De Medicamentos, Alimentos, Tecnologia, Medica, Argentina; APEC: Asia Pacific Economic Cooperation; API: Active Pharmaceutical Substance; ASEAN: Association of South East Asian Nations; ATMPs: Advanced Therapy Medicinal Products; BA: Bio-Availability; BD: Business Development; BE: Bio-Equivalence; BSE: Bovine Spongiform Encephalopathy; CAT: Committee for Advanced Therapy; CDSCO: The Central Drugs Standards and Control Organization, India; CHMP: Committee for Human Medicinal Products CMC- Chemistry, Manufacturing and Control; CMSs: Concerned Member States; COFEPRIS: The Federal Commission for the Protection against Sanitary Risk, Mexico; COMP: Committee for Orphan Medicinal Products; CRO: Clinical Research Organization; CT: Clinical Trial; CTD: Common Technical Document; CTRI: Clinical Trial Registry of India; CVMP: Committee for Veterinary Medicinal Products; DCA: Drug Control Administration, Malaysia; DPCO: Drug Prices Control Order DRA- Drug Regulatory Affairs; DMF: Drug Master File; eCTD: Electronic Common Technical Document; EC: European Community; EEC: European Economic Commission; EMEA: European Medicines Agency; EMR: Exclusive Marketing Rights; EU: European Union; FDA: Food and Drug Administration; FDCs: Fixed Dose Combinations; GCC: Gulf Cooperation Countries; GCP: Good Clinical Practices; GMPs: Good Manufacturing Practices; GRP: Global Regulatory Plan; HA: Health Authority; HPMC: Committee for Herbal Medicinal Products; ICH: International Conferences for Harmonization on Technical Requirements for the registration of Pharmaceutical for Human Use; ICMR: Indian Council of Medical Research; IMPs: Investigational Medicinal Products; IP: Intellectual Property; ICTRP: International Clinical Trials Registry Platform; IT: Information Technology; MA: Marketing Authorization; MAA: Marketing Authorization Application; MCC: Medicines Control Council, South Africa; MHRA: Medicines and Healthcare Regulatory Agency, UK; MHLW, Japan:
Ministry of Health, Labor and Welfare- Regulatory Authority; MPs: Medicinal Products; MRP: Mutual Recognition Procedure; MNCs: Multi National Companies NBA- New Biologics Application; NDA: New Drug Application; NIMS: National Institute of Medical Statistics; OTC: Over-The-Counter; PANDRH: Pan American Network on Drug Regulatory Harmonization; PCT: Patent Cooperation Treaty; PV: Pharmacovigilance; PvPI: Pharmacovigilance Programme of India; QA: Quality Assurance; QC: Quality Control; R\&D: Research \& Development; RLD: Reference Listed Drugs; RMS: Reference Member State; SADC: South African Development Community; SMF: Site Master File; SFDA: State Food and Drug Administration of Republic of China, China; SOP: Standard Operating Procedure; TGA: Therapeutic Goods Administration, Australia; TRIPS: Trade Related Intellectual Property Rights; TSE: Transmissible Spongiform Encephalopathy; UK: United Kingdom; USA: United States of America; USAD: United States Agriculture Department; USFDA: United States Food and Drug Administration, USA; USP: United States Pharmacopoeia; USPC: United States Pharmacopoeia Committee; VAMF: Vaccine Antigen Master File; WHO: World Health Organization.

*Corresponding author: Hasumati Rahalkar, Founder, Metina Consultants Navi Mumbai, Maharashtra, India, Tel: +91 226516 7719; Fax: +91 226793 9919; E-mail: hasumati@metinaconsultants.com

Received September 03, 2012; Accepted September 27, 2012; Published September 29, 2012

Citation: Rahalkar H (2012) Historical Overview of Pharmaceutical Industry and Drug Regulatory Affairs. Pharmaceut Reg Affairs S11:002. doi:10.4172/2167-7689. S11-002

Copyright: @ 2012 Rahalkar H. This is an open-access article distributed under the terms of the Creative Commons Attribution License, which permits unrestricted use, distribution, and reproduction in any medium, provided the original author and source are credited. 
Citation: Rahalkar H (2012) Historical Overview of Pharmaceutical Industry and Drug Regulatory Affairs. Pharmaceut Reg Affairs S11:002. doi:10.4172/2167-7689.S11-002

\section{Introduction}

The current Pharmaceutical Industry is well organized, systematic and compliant to international regulatory standards for manufacturing of Chemical and Biological drugs for human and veterinary consumption as well as medical devices, traditional herbal products and cosmetics. Stringent GMPs are being followed for blood and its derivative as well as controlled manufacturing for Traditional Herbal Medicines, Cosmetics, Food and Dietary products which was otherwise differently a century before. Each regulatory system had faced certain circumstances which led to current well-defined controlled regulatory framework. This has resulted into systematic manufacturing and marketing of safe, efficacious and qualitative drugs. With the growth of industry, the legislations from each region have become more and more complex and created a need for regulatory professionals. To understand the chronological development of the modern era of pharmaceutical industry and regulatory framework, we will glance through the historical evolution of regulations in USA, Europe and India.

\section{Objectives}

After reading this paper, you should be able to understand

- How and why the pharmaceutical industry and drug regulations have developed in USA

- Major Regulations of USA

EU and its regulatory framework

- Content of "The Rules Governing Medicinal Products in the European Union”

- Pharmaceutical Legislations of EU

EMEA and its Committees

Types of Marketing Authorization Procedure in EU

- Indian Pharmaceutical Industry \& Drug Regulations development in different Era

- Major Rules and Act of India

Drug Regulatory Affairs and Global, Regional and National Regulatory Network

- Roles of Regulatory Affairs Professional in Health Authorities as well as Pharmaceutical Industry

Regulatory Affairs Network in Pharmaceutical Industry

\section{Historical Overview of Pharmaceutical Industry}

During 1950s, multiple tragedies i.e. sulfanilamide elixir, vaccine tragedy and thalidomide tragedy have resulted in substantial increase of legislations for drug products quality, safety and efficacy. This has also resulted into stricter norms for Marketing Authorization (MA) and Good Manufacturing Practices (GMPs). Let us see what happened in USA, Europe and India.

\section{United States of America (USA)}

During the early Eighteenth century, chemical manufacturing factories had started establishing and the first large scale manufacturing of glycerine started during 1818-1840. However, with regard to medicines, it was being compounded by Pharmacists and Doctors at Pharmacy laboratories. Crude drugs i.e. opium were extracted from natural plants by compounding pharmacists and progressed further for identifying and isolating active ingredients from the crude drug.

In the USA, the root of modern pharmaceutical industry was borne during Mexican- American war 1846-1848. The American troops had suffered due to import of spurious medication for Malaria, Cholera, Dysentery, Yellow Fever and that had brought federal government into action for creation of Custom Laboratories. The first law which controlled import of medicines was Import Drugs Act of 1848. As per this law, it was mandatory to inspect imported drugs for quality and purity at the entry of port. To define the quality and purity of drug, federal government recognized United States Pharmacopoeia (USP) as an official compendium. Note that though United States Pharmacopoeia Committee (USPC) was established in 1820, it was non government body till Import Drugs Act of 1848. It was formed with the objective of creating system for standards, quality control and national formulary.

At the start of the nineteenth century, new legislations for medicines control started coming into effect due to multiple tragedies worldwide. This was the era when ancient traditions of manufacturing and distribution of drugs evolved into the modern highly organized pharmaceutical industry and controlled system of Drug Regulatory Affairs (DRA).

Almost five decades after issuance of Import Drugs Act of 1848, vaccines tragedy happened in 1901. During this era, City and State Health Departments use to maintain stables and vaccine preparation facilities unlike the private industry today. Legislations mandating exclusive manufacturing facility for vaccines enacted post two events of death due to immunization failure. The diphtheria antitoxin developed by City Health Department of St. Louis was contaminated by tetanus causing bacteria. This was ended up with the death of 14 children in November 1901. Simultaneously, smallpox vaccine administered was found contaminated and resulted into nine more death in Camden, New Jersey (Figure 1).

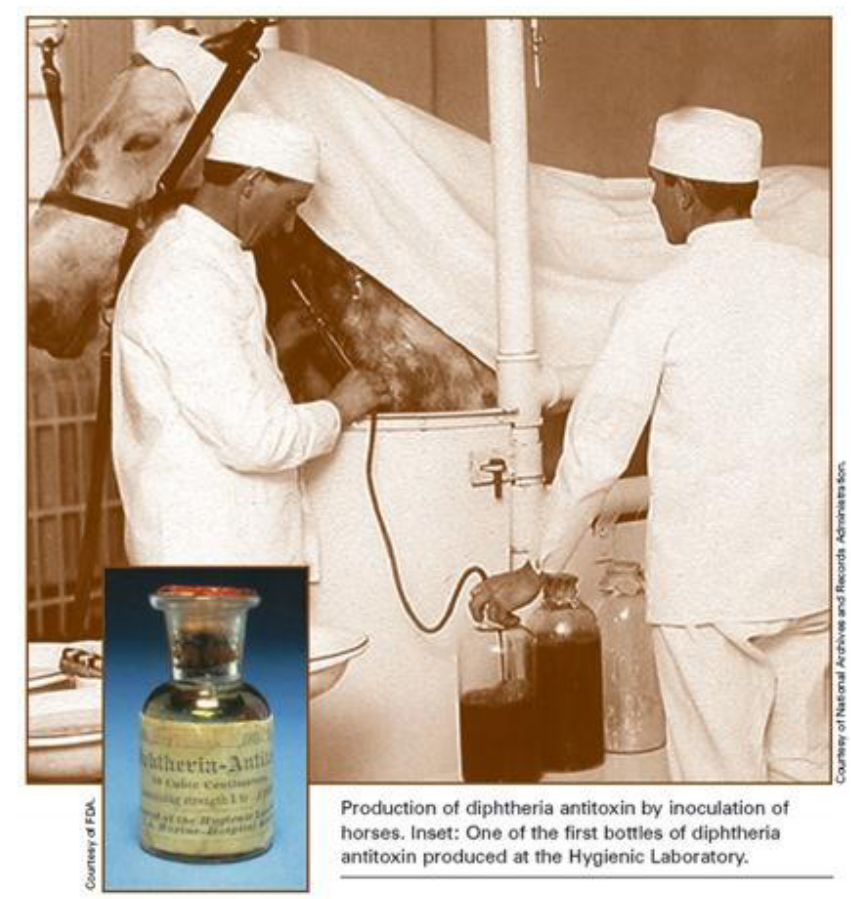

Figure 1: Vaccine Preparations at City Health Department. 
The Biologics Control Act of 1902 was the result of the vaccine tragedy. This legislation mandated manufacturing and distribution licensing of biological products i.e. serum, vaccine, toxin, viruses as well as defined labeling in terms of manufacturer's name, address, license number, identification of product and expiry date (Figure 2).

Proceeding further from Import Drugs Act of 1848 to The Biologics Control Act of 1902, federal government took steps for controlling adulteration or misbranding of foods, drugs, medicines, liquors. This law prohibited interstate transportation of adulterated food and drugs. With this law toxic colors and preservatives like borax, sulphuric acid, formaldehyde, copper and sulphate were banned for usage in food and drugs. The Food and Drugs Act of 1906 is best known as Wiley Act, named by Dr. Harvey W. Wiley. This law made mandatory labelling of ingredients and its content for drugs i.e. alcohol, cocaine, heroin, morphine, opium. This was the first wide ranging, national legislation on food and medicines safety (Figure 3).

The Federal Food and Drugs Act 1906 was starting point for eventual creation of Food and Drug Administration (FDA). Originally The Bureau of Chemistry was used to regulate food safety, however in 1927, it was reorganized into the Bureau of Chemistry and Soils and Food, Drug and Insecticide Administration. In 1930, the current Food and Drug Administration (FDA) came into effect after shortening of earlier organization. Since the root of FDA was born in 1906, FDA still celebrates 1906 as its establishment year.

From the above act, regulatory control on food and drug has increased drastically. However Sulfanilamide Elixir tragedy raised concern about the safety of drug products. In 1938, more than 100 people were died due to diethylene glycol (highly toxic solvent) utilised for mixing Sulfanilamide drug. Consequently, the law was enacted as Food, Drug and Cosmetic Act of 1938 to oversee safety of medicine. With this law, pre-marketing approval of all new drugs was made

EVOLUTION OF VACCINE INDUSTRY

Before Biologics Act
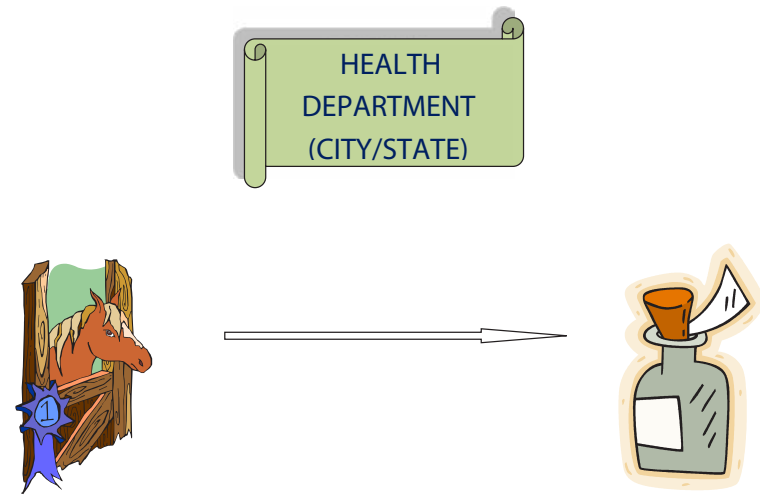

Horse Inoculation Sera collection

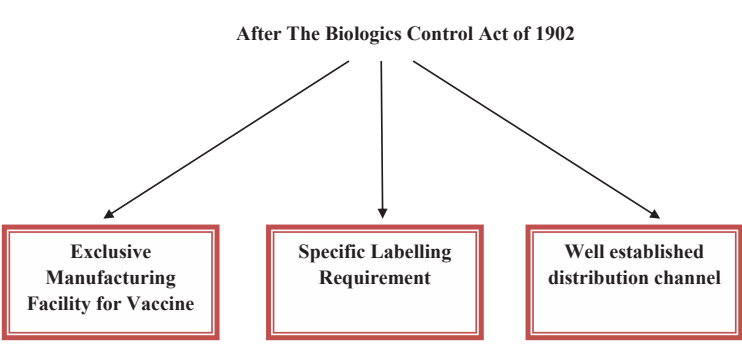

Figure 2: Evolution of Vaccine Industry.

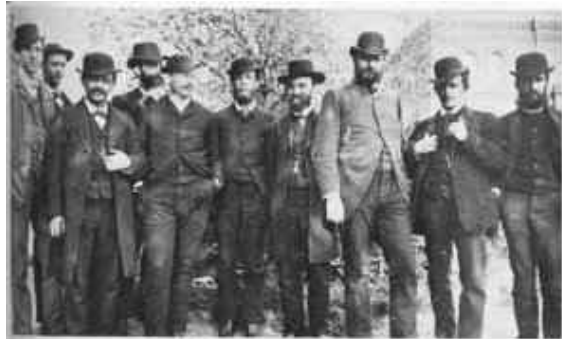

Figure 3: Dr. Harvey W. Wiley (last third from right) with chemistry department staff.

mandatory and proof for scientific safety study was asked by FDA. This law also mandated the directions for safe use (Figure 4).

Raising the bar of regulation, federal government issued a law for categorising medicines as Over-The-Counter (OTC) drugs and Prescription drugs which was not in place earlier. As per this law, medicines for minor ailments i.e. indigestion, headache can be fall under OTC drugs and freely sold at pharmacy store without prescription. Major ailments drugs are "Prescription Only (RX)" and unsafe for self medication. It was mandated to put statement a labeling as "Caution- Federal Law prohibits dispensing without a prescription". This law was known as Durham-Humphrey Amendment of 1951, best known as Prescription Amendment Act of 1951 (Figure 5).

Milestone changes happened on the basis of Kefauver-Harris Drug Amendments 1962. This was the after effect of Thalidomide tragedy in Western Europe. As per this law, new drugs were required to be supported with efficacy as well as greater safety data, Good Manufacturing Practices (GMPs) and prior Marketing Authorization Approval was mandated by FDA in these amendments [1].

Drug regulations evolved rampantly in last five decades and many laws came into effect which resulted into organized regulatory structure of FDA. The agency grew from single chemist from United Stated Agriculture Department (USAD) to approximately 9100 employees of varied category i.e. physicians, pharmacologists, chemists, microbiologists, pharmacists, veterinarian and lawyers. Currently, agency is responsible for protecting the public health by assuring the safety, effectiveness and security of human and veterinary drugs. It regulates over 1 trillion dollars worth of products in New Human Drug, Biologics, Biologics, Complex Medical Devices, Food and Color Additives, Infant formulas and Animal Drugs (Table 1).

\section{European union (EU)}

In European Countries, the healthcare regulations have developed with main objective of keeping unsafe products out of marketplace. In addition to Quality, Safety and Efficacy, few other factors were responsible for well defined legislation as well as highly advanced pharmaceutical industry.

Ethical considerations: To avoid unethical and unsafe clinical trials and have safe and proper treatment of human subjects, the Helsinki Declaration has been set in 1964.

Economic issues: First health insurance system was developed in later half of $20^{\text {th }}$ century. This has resulted in to pricing transparency due to the fact that cost of medicines was transferred from customer to private and public health insurance system.

Unsafe products usage: In European Countries, major revolution of drug regulations started post Thalidomide tragedy. In late 1950s, a German company was marketing new sedative pills throughout Europe 
Citation: Rahalkar H (2012) Historical Overview of Pharmaceutical Industry and Drug Regulatory Affairs. Pharmaceut Reg Affairs S11:002. doi:10.4172/2167-7689.S11-002

Page 4 of 11

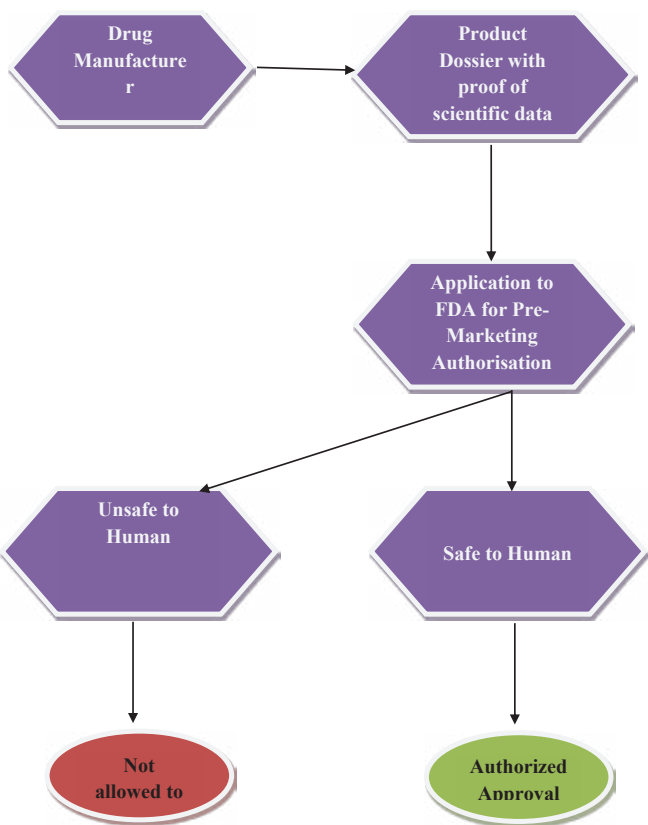

Figure 4: Pre-Marketing Approval for New Drugs.

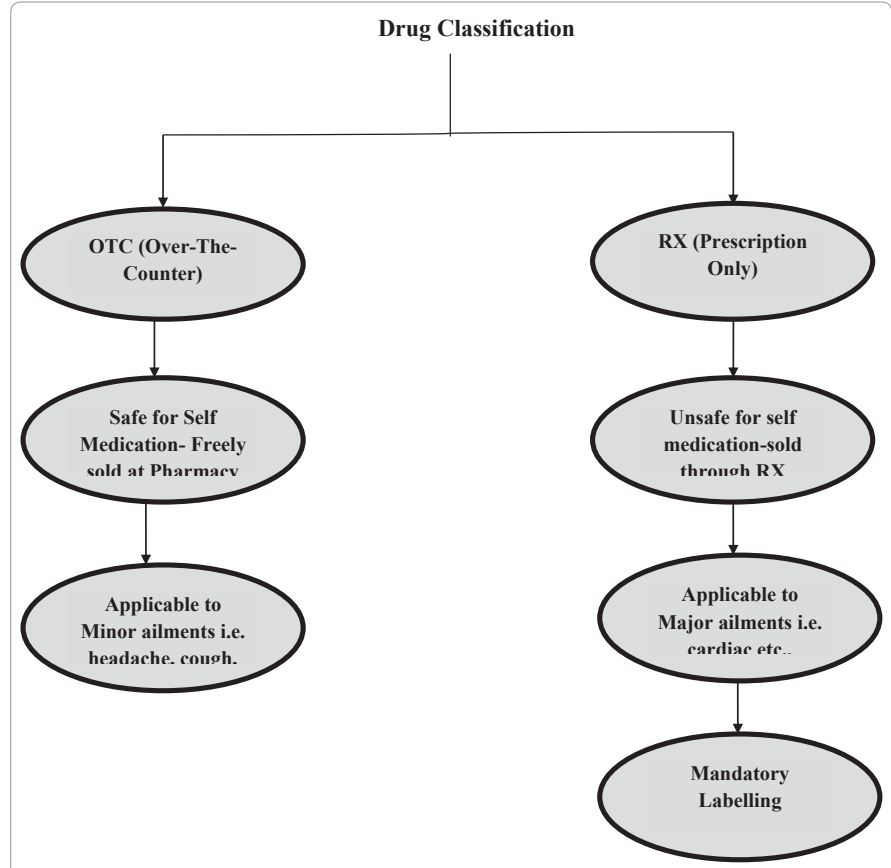

Figure 5: Classifications of Drugs.

that supposedly helped reduced nausea in pregnant women. While taking this drug during early pregnancy, it created teratogenic effect which resulted into birth defects in almost 10000 children. The babies born to women in Germany and England were without hands, feet, toes or fingers like flippers growing out of their shoulders and trunk.

Until Thalidomide tragedy, the drugs were being sold by notification to health authority and NO safety, efficacy or quality data were required to be submitted prior marketing. However, this has changed with the formation of European Economic Commission (EEC) in 1957 (Currently known as European Union-EU) (Figure 6).
The first directive passed by European Economic Commission was $65 / 65 /$ EEC mandating that no medicines can be marketed in European Communities until and unless it is not approved by at least one competent authority within Europe. The objective of this legislation was to have standard common marketing approval for medicines process within European Economic Commission. At the same time, few more directives specific to the category of products i.e. radiopharmaceuticals, immunological and homeopathic medicines as well as classification, labeling and promotion directives were came into effect.

Early 1990s in UK, Creuthfeldt-Jacob disease cases were started increasing. This is a human equivalent Bovine Spongiform Encephalopathy (BSE), commonly known as "mad cow disease". It was suspected that this disease was due to consumption of Bovine Spongiform Encephalopathy (BSE) infected beef. Based on this incidence, the legislation pertaining to Bovine Spongiform Encephalopathy (BSE) and Transmissible Spongiform Encephalopathy (TSE) free use of materials have come in to place. It is applicable to

\begin{tabular}{|c|c|}
\hline $\begin{array}{l}\text { Milestone Legislation and /or } \\
\text { Year }\end{array}$ & Objective \\
\hline 1820 & $\begin{array}{l}\text { United States Pharmacopoeia (USP) creation } \\
\text { as compendium } \\
\text { for recommended drugs listing }\end{array}$ \\
\hline Import Drugs Act of 1848 & To Control Import of Adulterated Medicine \\
\hline Biologics Control Act of 1902 & $\begin{array}{l}\text { To ensure safety and purity of biological } \\
\text { products i.e. } \\
\text { vaccines, serum and well defined labelling of } \\
\text { such products with license number }\end{array}$ \\
\hline $\begin{array}{l}\text { Food and Drugs Act of } 1906 \\
\text { or Wiley Act }\end{array}$ & $\begin{array}{l}\text { Ensures mandatory labelling of content and } \\
\text { ingredients on } \\
\text { food and medicine }\end{array}$ \\
\hline 1907 & $\begin{array}{l}\text { First Certified Color Regulations- listed seven } \\
\text { colors for use } \\
\text { in food }\end{array}$ \\
\hline Sherley Amendment, 1912 & Prohibit false therapeutic label claim \\
\hline $\begin{array}{l}\text { Food and Drugs Cosmetic Act } \\
\text { of } 1938\end{array}$ & $\begin{array}{l}\text { Scientific proof for safety of medicine prior } \\
\text { marketing, } \\
\text { Factory inspections and expanded for } \\
\text { Cosmetics and Medical device }\end{array}$ \\
\hline $\begin{array}{l}\text { Durham-Humphrey } \\
\text { Amendment Act of } 1951 \\
\text { (Prescription Amendment Act) }\end{array}$ & $\begin{array}{l}\text { Categorized Over-The-Counter and } \\
\text { Prescription Only } \\
\text { (RX)Drugs }\end{array}$ \\
\hline $\begin{array}{l}\text { Kefauver- Harris Drug } \\
\text { Amendments Act } 1962\end{array}$ & $\begin{array}{l}\text { Mandate to prove efficacy and better safety of } \\
\text { medicines }\end{array}$ \\
\hline Orphan Drug Act 1983 & $\begin{array}{l}\text { Enable for research and marketing of rare } \\
\text { diseases drugs }\end{array}$ \\
\hline $\begin{array}{l}\text { Drug Price Competition and } \\
\text { Patent Term Restoration Act } \\
1984\end{array}$ & $\begin{array}{l}\text { Application approval of less costly drugs by } \\
\text { giving waiver } \\
\text { for repeat safety and efficacy study, known as } \\
\text { generic drug. } \\
\text { Drug Innovator company can apply for up } \\
\text { to five years additional patent term, the time } \\
\text { consumed for FDA approval process. }\end{array}$ \\
\hline MedWatch System & $\begin{array}{l}\text { Creation of volunteer reporting of Adverse } \\
\text { reactions for } \\
\text { medicinal products }\end{array}$ \\
\hline $\begin{array}{l}\text { Uruguay Round Agreement } \\
\text { Acts } 1994\end{array}$ & $\begin{array}{l}\text { Extends patent term of US drugs from } 17 \text { years } \\
\text { to } 20 \text { years }\end{array}$ \\
\hline Paediatric Rule 1998 & $\begin{array}{l}\text { Suggest safety and efficacy of drugs \& } \\
\text { biologics in children }\end{array}$ \\
\hline $\begin{array}{l}\text { ClinicalTrials.gov foundation } \\
1999\end{array}$ & $\begin{array}{l}\text { To provide on-going clinical research } \\
\text { information to public }\end{array}$ \\
\hline
\end{tabular}

Table 1: List of Major Acts, Rules or System in USA. 


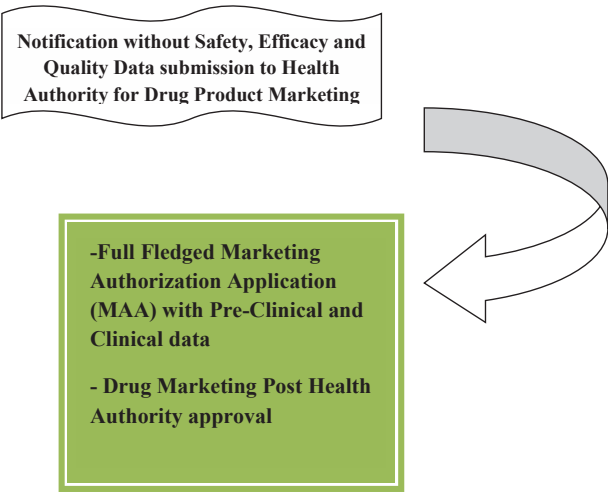

Figure 6: Gradual development of Marketing Approval System.

ingredients derived from bovine materials i.e. lactose, magnesium stearate, gelatin.

Free availability of information: Positive and negative news/ information about medicine is available almost to everyone due to wide spread use of media and World Wide Web (internet) network. To ensure public's confidence in healthcare system, regulations pertaining to quality, safety, efficacy and clear instructions for use came into effect.

Products and technology innovation: Development of new products such as biologics, blood and blood related products, and invitro diagnostics needed new legislations. It has led to the development of "concertation procedure" in 1987, where member states agreed to assess common Marketing Authorization Application (MAA).

Demands for products safety: Regulatory authority demands safety data to support Marketing Authorization (MA) as well as monitoring of safety data throughout the products post authorization cycle. New legislations have started coming in place due to public demand of improved quality of life as well as improved survival rate and longevity.

Changes in market structure: Healthcare regulations were required due to creation of single EU market by removing trade barrier. In this scenario, regulatory framework was varied from one country to another. Hence common regulatory framework was required. Since the market was open, the quality concern for imported products was arise and led to the development of new regulations.

\section{European commission (EC) regulatory framework}

First Legislation 65/65/EEC: In Europe the first pharmaceutical directive published by European Economic Commission was 65/65/ EEC. The main goals of this legislation were protection of human health and free movement of products among member states (Figure 7).

The current EU legal framework is available as series of volume published officially by European Committees as "The Rules Governing Medicinal Products in the European Union”. It gives complete clarity about regulatory framework of Europe Commission [2].

It is divided as below:

Pharmaceutical legislation: Currently, the EU legislation on medicinal products consists basically of Directives, Regulations, Decisions and Recommendations.

- Directives must be transferred into national law by the member countries prior to becoming effectives.

- Regulations apply directly in all member states.

\section{- Decisions \& Recommendations.}

Notice to applicants: Under this section, detailed requirements and understanding about marketing authorisation procedure (Evaluation process, query response and timeline) as well as dossier preparation and its content (CTD and eCTD) and related guidelines are available. This is non-binding texts to help applicants fulfils regulatory approval obligations to place drug products in market.

Regulatory guidelines: Under this section, regulatory guidelines i.e. Quality and Biotechnology, Safety, environment and information, as well as efficacy guidelines to support product development are available.

Detailed drug monitoring guide: Under this section, guidelines pertaining to drug monitoring (pharmacovigilance) for the medicinal products already approved are available.

\section{GMP Guide}

Under this section, requirements pertaining to GMP of manufacturing locations are available (Figure 8).

\section{Pharmaceutical legislations}

Pharmaceutical Legislations of EU are made up of 3 parts:

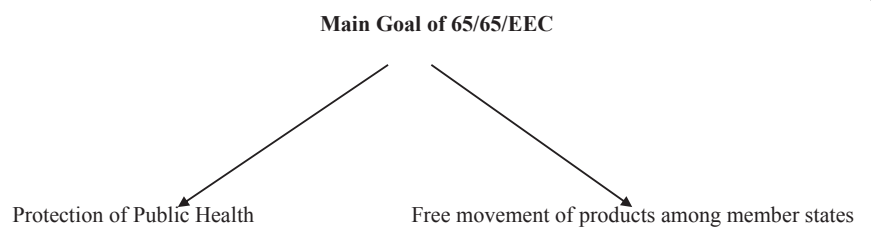

Figure 7: Goal of EEC.

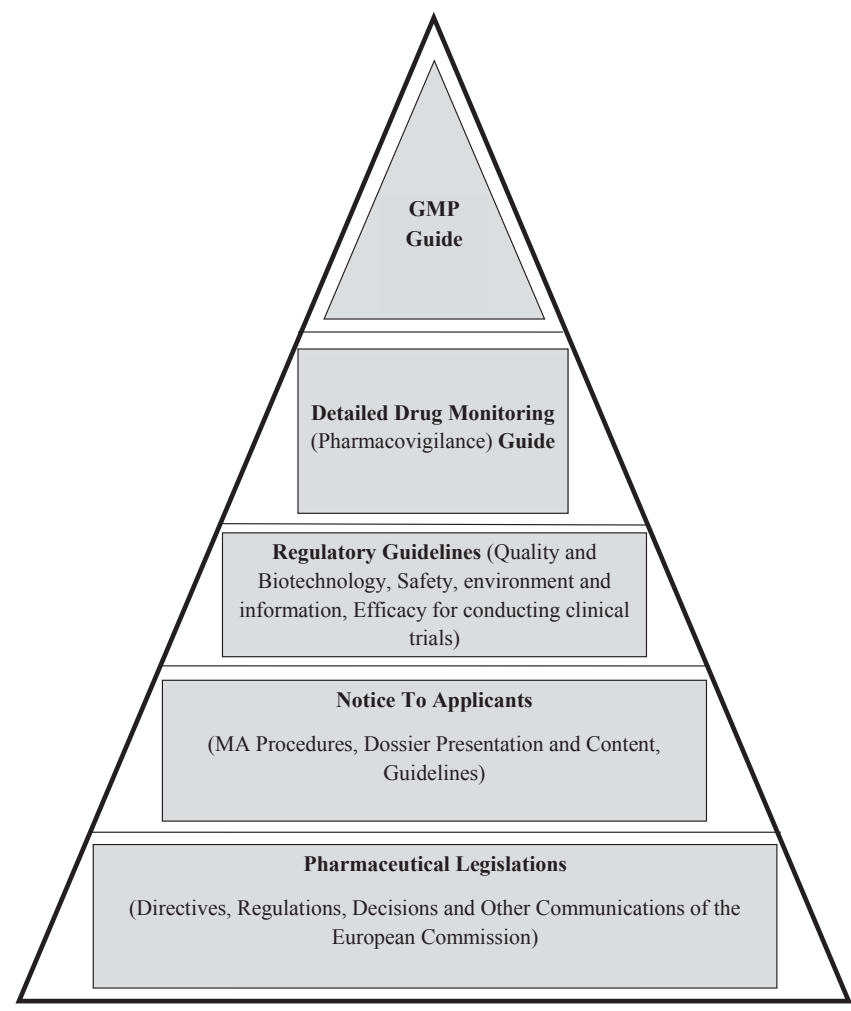

Figure 8: The Rules Governing Medicinal Products in the European Union. 


\section{A. Directives}

\section{B. Council Regulations}

C. Decisions and other communications of the European Commission

\section{Directives:}

a) Council Directive 65/65/EEC: Post 1964, Contegran sedative pill catastrophe, the first European medicinal council directive came into effect was 65/65/EEC. This was about detailed marketing authorisation requirements across European community came into effect.

In another five year, 1970, the directive was incorporated into national laws of each member states of EU. This directive was applicable not only to new products to be authorized but already approved marketed products as well.

b) Council Directive 75/318/EEC: This directive specifies legal requirements relating to analytical, pharmaco- toxicological, and clinical documentation.

Recently it has been amended by the requirements for minimising Transmissible Spongiform Encephalopathy (TSE) contamination risks.

c) Council Directive 89/342/EEC: It defines requirements for immunological products i.e. vaccines, toxins, sera and allergens.

d) Council Directive 89/381/EEC: Covers medicinal products derived from human blood and blood plasma.

e) Council Directive 91/356/EEC: It defines GMP requirements.

f) Council Directive 92/26/EEC: It defines prescription status.

g) Council Directive 92/27/EEC: It defines medicinal products labeling and package leaflet.

h) Council Directive 92/28/EEC: It defines medicinal products advertising.

i) Council Directive 2001/18/EEC: It regulates use of genetically modified micro organisms and their deliberate release into environment. This directive was further amended by regulations (EC) 830/2003- establishing a clear EU system for tracking and labeling genetically modified organisms.

"Above all Council Directive was unified and replaced by one common directive as 2001/83/EEC in 2001".

Further amendment done in 2001/83/EEC as below:

j) Council Directive 2002/98/EC: It defines standards of quality and safety for the collection, testing, processing, storage and distribution of human blood and blood products.

k) Council Directive 2003/63/EC: It defines analytical, pharmacotoxicological, clinical standards and protocol for medicinal products testing. With this directive, biological Medicinal Products safety was increased. It also establishes a new system that simplifies approval and subsequent change procedure for human plasma derived medicinal products as well as need for Vaccine Antigen Master File (VAMF).

1) Council Directive 2004/24/EC: This defines requirements for Traditional Herbal Medicinal products. This directive defines roles and responsibility of HPMC (Committee for Herbal Medicinal Product).

m) Council Directive 2003/94/EC: This directive was laid down further GMP principles and guidelines for Medicinal products and Investigational Medicinal Products (IMPs). n) Council Directive 2004/27/EC: This directive specifies GMP requirement for API process. It is further amended for labeling, packaging and MA changes. This directive is amended for improvisation of pharmacovigilance by database improvement and electronic notification system regarding adverse results.

\section{Council Regulations:}

a) Regulation (EC) 1901/2006: This regulation specifies Medicinal products for pediatric use and amendments. It also specifies established rules concerning development of medicinal products for human use, for specific therapeutic needs for pediatric population, without subjecting pediatric population to unnecessary clinical and other trials.

b) Regulation (EC) 1394/2007: This regulation specifies on Advanced Therapy Medicinal Products (ATMPs). It mandates to have EU wide Marketing Authorization (MA) for all advanced therapy products. It creates centralised supervision and pharmacovigilance of Advanced Therapy Medicinal Products (ATMPs). With this regulation, Committee for Advance Therapy (CAT) Medicinal product is responsible for guideline and evaluation criteria.

30 Dec 2008, the scope is expanded to gene, somatic therapy medicinal products as well as tissue engineered products.

c) Regulation (EC) 2309/93: EU implemented Pan-European registration system known as "Centralised Procedure" and established EMEA (European Medicines Evaluation Agency).

d) Regulation (EC) 726/2004: This regulation (2309/93) was further superseded by Regulation (EC) 726/2004 with improvement in authorisation procedure and amendment of certain administrative aspects.

e) Regulation (EC) 726/2004: This regulation has further expanded by application of centralised procedure to orphan drugs and products with new active substances, dealing with acquired immune deficiency syndrome, cancer, neuro- degenerative disorder, diabetes, autoimmune Diseases, immune dysfunctions and viral diseases.

EMEA and its Committees: With Regulation (EC) 726/2004, the European Agency for the evaluation of medicinal products was changed to European Medicines Agency keeping the same acronym as EMEA.

EMEA is a system which enables single medicinal product marketing authorization in entire EU. EMEA is head quartered in London and provides administrative support for MAA requirements for centralised procedures. EMEA is composed of five different committees and each committee is composed of regulatory agency responsible from each member states.

a) EMEA committees: 1 . Committee for Medicinal Products for Human Use (CHMP)
2. Committee for Medicinal Products for Veterinary Use (CVMP)
3. Committee on Orphan Medicinal Products (COMP)
4. Committee on Herbal Medicinal Products (HPMC)
5. Committee for Advanced Therapies (CAT)

\section{EU and Marketing Authorization Procedure:}

a) Centralised procedure: Under this procedure, Marketing Authorization Application is being reviewed by EMEA and approved to market for EU countries at once. Medicinal products that do not fall under Centralised Procedure, may receive marketing authorisation through one of the two mechanisms. 
b) National registration: This procedure is applicable when marketing authorization is required only in one EU country. The requirements, review process and timelines are governed by the individual member states.

c) Decentralised Mutual Recognition Procedure (Commonly known as Mutual Recognition Procedure- MRP): This procedure is applicable when marketing authorization is required for more than one EU country. In this process, Marketing Authorization Application (MAA) is reviewed by one member country as decided by manufacturer and titled as "Reference Member State (RMS)". If Marketing Authorisation is granted by RMS, than other states as defined by manufacturer would be titled as "Concerned Member States (CMSs)" and are asked to mutually recognise the RMS approval. If approval is recognised, MA will be granted in all the CMSs.

Decisions and other communication of european commission: Decisions are the measures, intended to bind individual pharmaceutical manufacturers /member states. EU also published non binding recommendations and opinions and express committee view.

Post thalidomide tragedy, directives and regulations are kept on expanding and today the scope has widened for medical devices, traditional herbal medicines, cosmetics, food \& dietary products.

India: The drug industry in India was at very primitive stage till $20^{\text {th }}$ Century. Most of the drugs were imported from foreign countries. Post First World War, the demand for drugs had increased tremendously and that led to the cheap \& substandard drugs into the market, as like in USA post Mexican American war [3].

a) 1900-1960: To control cheap drugs in market, Government passed the Poisons Act 1919. This Act regulates possession of substance or sale of substances as specified as poison. It also specifies the safe custody of the poisons, labeling and packaging of poisons, maximum quantity to be sold and inspection as well as examination of the poison sold by vendor during the year.

The Poisons Act was followed by The Dangerous Drugs Act 1930. This act regulates the opium plant cultivation, manufacture and possession of opium, its import, export, tranship and sell of opium.

The Narcotics and Psychotropic Substances Act was passed in 1985 which revoked the Dangerous Drugs Act 1930 and Opium Act, 1878. Following acts \& rules were passed during this era:

- Drugs and Cosmetics Act, 1940: Regulate the import, manufacture, distribute and sale of drugs. This act covers allopathic, homeopathic, Unani and Sidha drugs.

- Drugs and Cosmetics Rules, 1945: The rules under the Drugs and Cosmetics Act regulate only manufacture of Ayurvedic drugs for sale, and not for consumption, use or possession.

- Pharmacy Act, 1948: This law was amended lastly in 1986 and it regulates the pharmacy profession of India.

- Drugs and Magic Remedies (Objectionable Advertisements) Rules, 1955: This rules control the drug advertisement in India.

- Drugs Prices Control Order, 1955 (DPCO) (under the essential commodities Act): DPCO was further amended in 1995. Under this rule, government may review and fix maximum sale price for bulk drugs as well as formulation.

b) 1960-1970: The market share was dominated by multinational companies and very few indian manufacturers were present. The Indian Pharmaceutical industry was in an early stage of growth. Focus for pure research and development was very little due to lack of patent protection. Due to very high import dependency on drugs, the cost of drugs was very high as well as market availability was comparatively low.

c) 1970-1980: Government took control for the medicines regulation and issued few acts and rules.

- Indian Patent Act 1970: It serves as the basis for patent protection in India. Based on this, only process and method of manufacture of Drug substance was allowed to get the patent. Product patent was not allowed under this act. Indian Patent Act of 1970 came into force from April 20, 1972. This new act replaced the Indian Patents and Designs Act of 1911.

- Drug prices capped: Drug Prices Control Order (DPCO) was introduced to control the high price against consumers.

- Local companies begin to make an impact: Since the product patent was allowed by Indian Patent Act 1970; local companies began manufacturing products/ drugs using different manufacturing process by reverse engineering. Due to this new drugs were available cheaply as well as many more substitute drugs were available in the market against costly imported new drugs. This has resulted in 1) increase the exports to countries like Russia, Africa, China, and South America. 2) Export of Bulk drug post patent expiry.

d) 1980-1990: The industry has started investing in API process development and created production infrastructure. Government has also issued export incentives. The Narcotic Drugs and Psychotropic Substances Act, 1985 was issued which regulates the operation of narcotic drugs and substances.

e) 1990-2000: The pharmaceutical industry has observed a rapid expansion of domestic market and during same era globalisation happened. The companies have entered into research activity.

India joined Paris Cooperation Treaty (PCT) in 1999 and implemented product patent effective from Jan 1, 2005.

f) 2000-2010: This period is considered to be the Innovation and Research era. During these years, innovative research activity, patenting of the drugs formula, process, indication as well as merger of companies was started.

- Patent Amendment Act 2005: With this act, provision for Black Box Application made, as per that if patent application is filed before Jan 1, 2005, then under the transit provision of Trade Related aspects of Intellectual Property Rights (TRIPS), manufacturer can market this product post 2005 without infringing product patent, if manufacturer has made significant investment in manufacturing of the product, produced and marketed on or before Jan 1, 2005.

- Compulsory Licenses: Such licenses can be granted for manufacture and export of the drug products "to any country having insufficient or no manufacturing capacity, for the said product, to address public health problems".

Herbal preparations having medicinal values can be patented under new amended law.

Major regulatory changes in terms of marketing authorization process as well guidelines have come into effect. Few to name are as below:

- Drugs and Cosmetics (First Amendment) Rules, 2011: 
It mandates registration of Clinical Research Organization (CRO) for conducting Clinical Trials (CT). Schedule Y1 suggests requirements and guidelines for registration of Clinical Research Organizations.

- Clinical Trial Registry- India (CTRI): It has been set up by the ICMR's (Indian Council of Medical Research) National Institute of Medical Statistics (NIMS). India has developed on-line registry system and mandated registration of CRO before the enrolment of first patient for clinical trials. CRO needs to disclose mandatory items as mentioned under WHO International Clinical Trials Registry Platform (ICTRP) dataset.

- Pharmacovigilance Programme of India (PvPI): The Central Drugs Standard Control Organization (CDSCO) has launched Pharmacovigilance programme to assure drugs safety to indian patients. This will help monitoring adverse drug reactions to indian patients, as well as monitoring of benefit-risk ratio.

- Guidance documents: CDSCO has issued guidance for Industry for Fixed Dose Combinations (FDCs) registration as well as Guidance for preparation of Common Technical Document for Import/manufacture and Marketing Approval of New drugs for Human Use (New Drug Application-NDA).

With this CDSCO has implemented system for preliminary scrutiny at the time of application receipt for marketing approval of Fixed Dose Combinations (FDCs).

\section{Drug Regulatory Affairs}

\section{Introduction}

As we have seen that from previous part of this chapter, legislations for marketing authorization as well as standards and quality of drugs are becoming more and more demanding and complex. Unlike earlier days, drugs are being developed for specific market keeping regulations of that country or region in mind. Without fulfilling requirements of law of land, it is practically impossible to have drug products in market. It is not stopping till initial marketing approval of the product but it goes beyond that and demands management of approval by submitting post marketing surveillance data, variation application and renewal during the approval life cycle of product.

Due to rapid increase in laws, regulations and guidelines for reporting safety, efficacy and quality of new medicinal products, necessity for expert regulatory professional arises tremendously. None of the drug manufacturing / marketing units are able to launch drug in market until and unless respective health authority (national / international) give green signal in writing.

Almost two decades before, drug regulatory affairs was least known / needed by pharmaceutical industry. It was in very nascent stage where registration executives were working under export department. However, the situation has changed drastically where fully fledged Global Regulatory Affairs department become mandatory to define drug development, approval and marketing strategy. Hence, the scope of Drug regulatory affairs has become vast and experts are needed in health authorities and pharmaceutical industry at various levels and departments.

Different regions have come together to form the Union so as to have harmonized regulatory requirements for particular regions and have same quality drugs available for all patients. i.e. European Union, Gulf Co-Operative Countries (GCC), Association of South East
Asian Nations (ASEAN). It is very difficult to segregate the markets like regulated, semi regulated or less regulated since the technical requirements for all markets are more or less same as well as the drug approval period is 18-24 months for majority of the markets. At the same time, the regulation pertaining to pharmcovigilance requirements mandates companies to monitor new drugs safety aspects throughout the life cycle of product. In this scenario, the role of regulatory expert is very critical and important for deciding the entry strategy into various national and international markets.

\section{Definition}

Drug Regulatory Affairs is a function which regulates the pharmaceutical science in order to facilitate trade / business in and outside the country of origin for public interest.

\section{Regulatory Network}

Drug Regulatory Affairs regulate pharmaceutical business through designing appropriate laws (rules) and enforcing the same so that the drugs meeting the highest standards of Quality are brought into the Global Trade. Rules and regulations are being prepared considering Global, Regional and National pharmaceutical trade as well as necessity of the drugs based on patient population (Figure 9).

Most of the national guidelines for drug development and marketing authorization application are defined based on Global and Regional Harmonized guidelines.

To understand it better, let's see

-Global Regulatory Network

-Regional Regulatory Network

-National Regulatory Network.

Global Regulatory Network: Global regulatory network are defined by regulatory representative of each country in the world (Figure 10).

ICH in collaboration with USA, EU and Japan issues Harmonized technical requirements for manufacturers to follow for MAA in these three regions.

WHO is comprise of balance all countries of world (except USA, EU and Japan) and prepares harmonized MAA guideline and technical data requirement for registration in all countries.

Regional Regulatory Network: To facilitate trade within specified regions, countries have come together and form a common trade association.

Regional trade associations define rules and regulations for

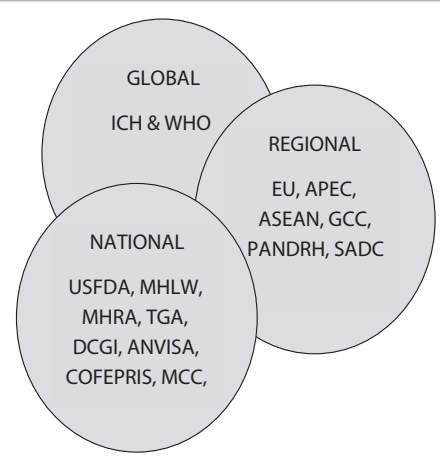

Figure 9: Worldwide Regulatory Network. 


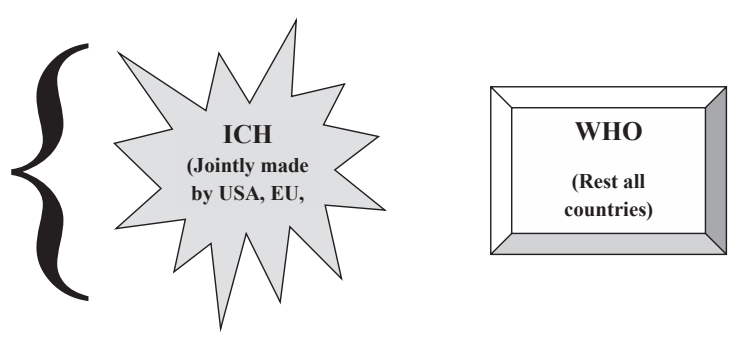

Figure 10: Global Regulatory Network.

common marketing authorisation application as well as technical data requirement for Pre-marketing authorization (Figure 11).

- ASEAN- Association of South East Asian Nations SADCSouth African Development Community

- APEC- Asia Pacific Economic Cooperation

- GCC- Gulf Cooperative Countries

- PANDRH- Pan American Network on Drug Regulatory Harmonization

- EU- European Union

National Regulatory Network: National Government issues mandatory laws based on healthcare status in respective country and at par with global and regional legislation to regulate healthcare business (Figure 12).

Few Examples of National Regulatory Authority:

- United States Food and Drug Administration- USFDA,

- Ministry of Health, Labor and Welfare, MHLW-Japan

- Medicines and Healthcare Regulatory Agency, MHRA-UK

- Therapeutic Goods Administration, TGA-Australia Medicines Control Council, MCC-South Africa

- The Central Drugs Standards and Control Organization CDSCO-India,

- State Food and Drug Administration of Republic of China, SFDA-China

- Agencia National De Vigilancia Sanitaria, ANVISA-Brazil

- Russian Federation, Russia

- The Federal Commission for the Protection against Sanitary Risk, COFEPRIS-Mexico

- Administration Nacional De Medicamentos, Alimentos, Tecnologia, Medica, ANMAT- Argentina

- Drug Control Administration, DCA-Malaysia

a) Health Authority (HA): HA prepares drug regulatory guidelines and guidance documents which are compliant to existing laws. HA coordinate with Global and/or regional regulatory body and in consultation with Pharmaceutical Manufacturer's Association issues technical requirements and process for Marketing Authorization Approval.

b) Pharmaceutical Industry: Manufacturer develops drug according to regulatory necessity of quality, safety and efficacy and apply for Marketing Authorization.
Here, the Regulatory Advisor plays a vital role by keeping himself/ herself updated with latest regulatory norms (national, regional and global), updating organization, defining regulatory strategy and applying for MAA."Drug Regulatory Affairs professional is a link between Health Authorities and Pharmaceutical Industry!!!”

\section{Roles of regulatory affairs professionals}

Regulatory Affairs advisor plays important portfolio in Health Authority as well as Pharmaceutical Industry.

Role of Regulatory Affairs Professionals in Health Authorities (HA): a) Evaluation of MAA:

1. Evaluation of Marketing Authorization Application i.e. New Drugs Application, New Biologics Application, Medical Device and Cosmetics application, Generic Application, Clinical Trial Application, Variation Application, Drug Master Files for API, Excipients and Packaging Materials, Site Master File for GMP inspection.

2. Issuance of Evaluation comments/ Exigencies to Manufacturers

3. Managing variation application, post approval changes and keeping record of annual update

4. Post Marketing Approval Management

5. Issuance of Marketing Authorization Approval, GMP, and GCP approval certificate

6. Managing MAA On-line and up-gradation towards common technical document format

b) Input for guidelines and guidance documents:

1. Issuance of guidelines \& guidance documents for Quality, Safety, Efficacy and

Pricing Control as well as CTD for implementation

2. Collaboration with Global and Regional Harmonization units for exchange of technical knowledge, developing guidelines as well as allotting mutual recognition status for technical documents, GMP status and product approval

3. Part of foreign trade delegation to facilitate smooth management of Pharmaceutical business within countries and minimising barrier by reducing duplicate generation of technical data and timeline for evaluation and approval by respecting each other regulatory framework

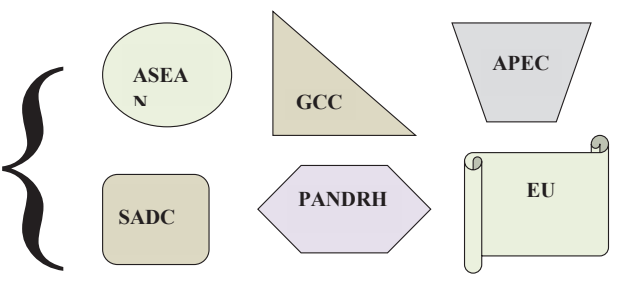

Figure 11: Regional Regulatory Network.
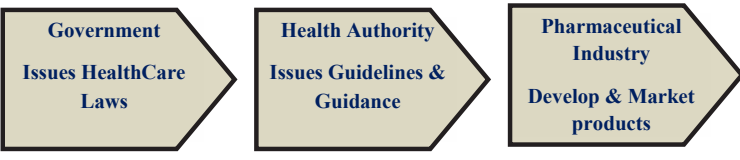

Figure 12: National Regulatory Framework. 


\section{c) Inspection:}

1. Performing GMP Audit for Drug Manufacturing Site, GCP Audit for Clinical Study Site and Bio-equivalence Centre, and issuing certification confirming approval status.

\section{d) Support to Pharmaceutical Manufacturers:}

1. Supporting Manufacturer in defining drug development pathway during Pre-NDA meeting and providing comments / confirming development pathway

2. Time to time meeting with pharmaceutical manufacturers association to discuss ongoing challenges, technical issues, guidelines/ guidance documents discussion and future development

e) Monitoring of Drug Safety and Efficacy:

1. Monitoring Drug Safety by collecting Pharmacovigilance data and reviewing drugs in markets time to time by reviewing labels and taking appropriate action accordingly

2. Monitoring Clinical Trials as well as approving study results for next phase of study

3. Allowing speedy or fast track designation for essential drug to patient population

Role of Regulatory Advisor in Pharmaceutical Industry: a) Define Regulatory Strategy for drug development: Based on the intended market; regulatory strategist plays an active role in below areas

1. Critical role during selection of Drug products for specific market

2. Be a part of Business development, Marketing and Project team meeting

3. Defines the type of application in consultation with specified Health Authority i.e. New Drug or Generic Application

4. Meet Health Authority/ies to define Clinical Regulatory Pathway

5. Based on that prepares Global Regulatory Plan (GRP) defining Chemistry, Manufacturing and Control (CMC), Clinical and Non-Clinical Requirements

6. Advise Research and Development (R\&D) team to develop product at laboratory scale matching regulatory criteria. In case of Generic drug, regulatory strategist advise which Reference Listed Drug (RLD) to be used, Test Criteria and Specifications for Active Pharmaceutical Ingredient (API) and Drug

Product for different kind of dosage forms, Stability data requirement of specified climatic zone (Zone I-IV) for Drug substance and Drug Product, Analytical Validation requirement, in-vitro equivalence data

7. Support in terms of executing validation batches at manufacturing location, defining batch size, number of batch sizes, criteria and justification for specification, evaluation of technical data

8. Bio-equivalence (BE) or Bio-Availability (BA) criteria- defining study protocol and getting concurrence from respective health authority

9. Labeling Requirement- for Generic submission, replica of innovator labeling information. In case of new drug, labeling to be based on actual Clinical and non clinical study
10. Applying for Site inspection for Good practices confirmation. For Manufacturing site- GMP certification, For BE and Clinical Site- GCP certification

\section{b) Marketing Authorization Application:}

1. Deciding the submission type- New Drug Application (NDA), New Biologic Application (NBA), Clinical Trial Application (CTA), Generic Application, Branded Generic Application, Post Approval Changes, Variation Application

2. Type of Drug Master files (Type I-IV) - Active Substance Drug Master File (DMF), Site Master File (SMF), Packaging Material Master File and Excipient Master files

3. Preparing Dossier in acceptable national format or Common Technical Dossier (CTD) format for Global submission

4. Justifying dossier application with Other Regulatory Agency's recommendation and precedence as well as Global and regional requirement

5. Formal application to respective Health Authority for MAA

6. Technical evaluation and support to manufacturing location and clinical sites during authority inspection

7. Drafting Query/Exigency's response to HA in time with prior discussion, need base

8. Support for Drug submission /approval calendar preparation and predicting Approval timeline for Drug Product and aligning marketing department for launch schedule

9. Managing Drug Product Registration Life Cycle by timely submission of post approval changes, Annual Update and Renewal submission

10. Submitting Pharmacovigilance data to Health Authority for already marketed drug

11. Withdrawal or cancellation application for drug, in case mandatory

c) Health Authority relationship:

1. Part of Health Authorities meeting to play advisory role in terms of defining guidelines from Industry point of view

2. Comments and suggestions for draft guidelines and circular, as applicable

3. Develop good working relationship with evaluators of Health Authority

4. Keeping updated about latest regulatory guidelines and upcoming changes to take proactive steps for alignment of manufacturers with regulations

d) Regulatory systems and processes:

1. Keeping records for Drug Product Submission and Approval database

2. Preparing Standard Operating Procedure (SOP) for efficient management of drug regulatory affairs department

3. Providing internal training to staff to keep up breast about regulatory environment

4. Be part of Regulatory forums/ conferences/ webinars / seminars to exchange regulatory knowledge 


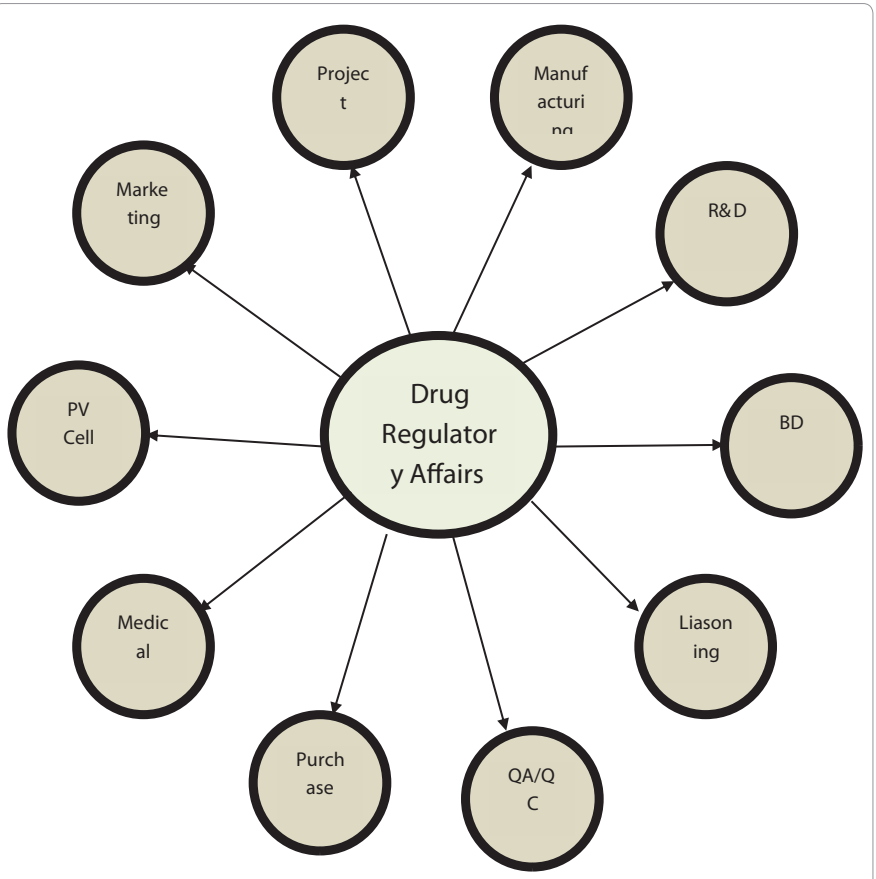

Figure 13: Drug Regulatory Affairs Network in Pharmaceutical Industry.
5. Organize proper storage of submission documents through Information Technology (IT)

6. Arrange software for on-line submission in Common Technical Dossier (CTD) format

Drug Regulatory Affairs (DRA) Network in Pharmaceutical Industry

Drug Regulatory Affairs have become a very important department for any pharmaceutical company (Figure 13).

\section{Further Reading}

Law relating to Drugs and Cosmetics by Vijay Malik, Twentieth Edition

Fundamentals of EU regulatory Affairs- Fourth Edition, Regulatory Affairs Professionals Society (RAPS)

\section{References}

1. http://www.fda.gov/AboutFDA/WhatWeDo/History/Milestones/default.htm

2. http://www.ema.europa.eu

3. http://cdsco.nic.in/ 